\title{
Analisis Campuran Lumpur dan Tetes Tebu pada Briket Tinja Hewan dengan Metode Taguchi
}

\section{Analysis of Mixed Sludge and Sugarcane Drops on Animal Fecal Briquettes Using the Taguchi Method}

\author{
Febi Rahmadianto ${ }^{1 *}$, Gerald A. Pohan ${ }^{2}$ Eko Edy Susanto ${ }^{3}$ \\ 1,2,3 Institut Teknologi Nasional Malang, Indonesia
}

Diterima: 22-09-2020 ; Disetujui: 07-03-2021 ; Diterbitkan: 06-05-2021

*Corresponding author: E-mail: rahmadianto15@gmail.com

\begin{abstract}
Abstrak
Energi terbarukan dikembangkan untuk mengurangi pemakaian bahan bakar fosil yang mulai menipis. Salah satu usaha penggunaan energi alternatif adalah dengan membentuk briket biomassa. Briket digunakan sebagai bahan bakar alternatif pengganti bahan bakar fosil. Dengan menggunakan briket, kebutuhan energi fosil bisa dikurangi. Dalam penelitian ini, briket memanfaatkan bahan limbah pertanian dan ternak. Indonesia memiliki wilayah yang sangat subur untuk budidaya dan peternakan yang dapat digunakan sebagai bahan baku biocharcoal. Bahan briket dengan berat 1 kg menggunakan campuran arang tinja ayam (variasi 30\%, 40\%, dan 50\%) yang dicampur dengan tetes tebu (variasi 10\%, $20 \%$, dan 30\%) dan lumpur lapindo (variasi 20\%, 30\%, dan 40\%). Briket ditekan dengan beban sebesar 80 kgf selama 1 menit. Nilai kalor pada spesimen untuk masing-masing variasi spesimen diinvestigasi. Dalam penelitian ini, faktor-faktor yang paling mempengaruhi nilai kalor dianalisa. Komposisi arang tinja, tetes tebu, dan lumpur dicari untuk memperoleh nilai kalor terbaik.
\end{abstract}

Kata Kunci: Alternative Renewable Energy, Biomass, Heating Value

\begin{abstract}
Renewable energy is developed to reduce the consumption of fossil fuels which are running low. One of the efforts to utilize alternative energy is to form biomass briquettes. Briquettes are used as an alternative fuel to replace fossil fuels. By using briquettes, fossil energy needs can be reduced. In this study, briquettes were made of agricultural and livestock waste materials. Indonesia has a very fertile area for cultivation and livestock that can be used as raw material for biocharcoal. The briquette material weighing $1 \mathrm{~kg}$ uses a mixture of chicken feces charcoal (variations of 30\%, 40\%, and 50\%) mixed with molasses (variations of $10 \%, 20 \%$, and 30\%) and Lapindo mud (variations of 20\%, 30\%, and 40\%). The briquettes were pressed with a load of $80 \mathrm{kgf}$ for 1 minute. The heating values of the specimens for each variation in the specimen were investigated. In this study, the factors that most influence the heating value were analyzed. The composition of feces charcoal, molasses and mud is investigated to obtain the best heating value.
\end{abstract}

How to Cite: Rahmadianto, F., 2021, Analisis Campuran Lumpur dan Tetes Tebu pada Briket Tinja Hewan dengan Metode Taguchi, JMEMME (Journal of Mechanical Engineering, Manufactures, Materials and Energy), 5 (01): 91-95 


\section{PENDAHULUAN}

Energi merupakan kebutuhan yang sangat penting bagi kehidupan manusia. Kebutuhan sumber energi sangat tergantung kepada bahan bakar minyak bumi maupun gas alam yang konsumsinya terus meningkat seiring perkembangan zaman[1]. Penggunaan sumber energi alternatif dapat menjadi solusi untuk mengurangi pemakaian energi fosil dan membantu dalam melestarikan lingkungan sekitar[2]. Belakangan ini, beberapa penelitian memfokuskan pada penggunaan material limbah dalam rangka meminimalisasi dampak negatif terhadap lingkungannya [3][4][5][6][7].

Salah satu cara dalam memanfaatkan sumber energi terbarukan yaitu dengan produk biomassa. Biomassa merupakan limbah padat yang dapat dimanfaatkan sebagai sumber bahan bakar alternatif dan ketersediaan energinya dapat diperbaharui (renewable energy) [3][5][6][8]. Untuk membuat biomassa limbah pertanian lebih bermanfaat sebagai bahan bakar alternatif dapat dilakukan dengan proses karbonisasi dan pembriketan[9]. Pengolahan biomassa menjadi briket bioarang akan menambah nilai bakar pada briket, sehingga lebih efisien dan maksimal dalam penggunaannya. Sifat-sifat penting briket meliputi nilai kalor, laju pembakaran, laju massa, dan berat jenis.

Pemanfaatan limbah peternakan dan pertanian merupakan salah satu alternatif yang sangat tepat untuk mengatasi naiknya harga dan kelangkaan bahan bakar minyak [10][11][12]. Namun sampai saat ini pemanfaatan kotoran ternak dan limbah pertaniaan sebagai bahan bakar alternatif belum dilakukan secara optimal [13]. Dalam konteks ini pemanfaatan kotoran ternak dan limbah pertanian sebagai sumber energi alternatif merupakan langkah yang sangat penting untuk menanggulangi ketergantungan terhadap bahan bakar minyak bumi (fosil)[14] [15]. Ternak tersebut akan menghasilkan kotoran yang belum dimanfaatkan secara maksimal .

Salah satu limbah pertanian yang pemanfaatannya belum maksimal adalah ampas tebu. Limbah ini biasanya dibuang oleh petani, padahal peneltian sebelumnya menunjukkan bahwa ampas tebu memiliki potensi untuk dikembangkan menjadi biomassa [5]. Oleh karena itu penelitian lebih lanjut perlu dilakukan untuk meningkatkan nilai kalornya dalam rangka mengurangi kebutuhan akan sumber energi fosil.

Dari penelitian sebelumnya, briket bioarang campuran sekam padi - kotoran ayam mempunyai potensi untuk dikembangkan menjadi bahan bakar, selain bahannya mudah didapat dan murah, energi yang dihasilkan juga cukup tinggi [11][16]. Dengan adanya pembahasan mengenai campuran pada briket tinja ayam sebelumnya, penulis mendapatkan gagasan untuk melakukan uji eksperimen pada briket tinja ayam dengan campuran tetes tebu dan lumpur lapindo. Hal tersebut bertujuan untuk mengetahui besar kalor pembakaran briket campuran arang tinja ayam dengan tetes tebu dan lumpur lapindo.

Tujuan penelitian ini ialah analisis terhadap pengaruh rasio campuran arang tinja ayam dengan tetes tebu, lumpur lapindo dan, tetes tebu + lumpur lapindo dalam briket dan analisis proses pembakaran dalam briket. Hasil penelitian yang diharapkan ialah dapat diketahui hubungan antara kenaikkan nilai kalor, laju pembakaran, dan laju massa pada proses pembakaran briket. 


\section{METODE PENELITIAN}

Spesimen terdiri dari 3 bahan, yaitu arang tinja, tetesan tebu, dan lumpur Lapindo. Variasi arang tinja adalah 30\%, 40\%, dan 50\%, variasi tetesan tebu adalah 10\%, 20\%, and $30 \%$, sedangkan variasi lumpur Lapindo adalah 20\%, 30\%, and 40\%. Berat masingmasing spesimen adalah $1 \mathrm{~kg}$. Spesimen dibuat melalui proses penekanan dengan beban sebesar 80 kgf yang ditahan selama 1 menit. Uji pembakaran dilakukan sebanyak 3 kali pada setiap sspesimen untuk memperoleh nilai kalornya. Data hasil pengujian kemudian diolah dengan metode Taguchi untuk mencari faktor yang paling berpengaruh terhadap nilai kalor briket. Selain itu, analisis dengan metode Taguchi dimanfaatkan untuk mencari komposisi persentase terbaik dari arang tinja, tetesan tebu, dan lumpur Lapindo.

\section{HASIL DAN PEMBAHASAN}

Data analisis dengan metode Taguchi yang diperlihatkan pada tabel 1 menunjukkan bahwa ketiga faktor yaitu arang tinja, tetes tebu, dan lumpur dapat di urutkan berdasarkan nilai ranking. Hasil tersebut menunjukkan bahwa tinja ayam memiliki pengaruh terbesar terhadap nilai kalor, diikuti dengan tetes tebu, kemudian dengan lumpur Lapindo. Berdasarkan desain eksperimen Taguchi hasil grafik main Effect Plot for Means dengan pendekatan larger is the better seperti diperlihatkan pada gambar 1, kondisi optimal dalam komposisi terpilih untuk nilai kalor terbesar pada tinja ayam $50 \%$, dengan tetes tebu 30\%, dengan lumpur Lapindo 40\% akan memberikan hasil terbaik dalam nilai kalor briket.

Tabel 1. Nilai kalor hasil uji pembakaran briket.

\begin{tabular}{|c|c|c|c|c|c|c|}
\hline \multirow[b]{2}{*}{ No. } & \multicolumn{3}{|c|}{ Rasio Campuran (1Kg) } & \multirow[b]{2}{*}{$\begin{array}{c}\text { Q1 } \\
\text { (kkal) }\end{array}$} & \multirow[b]{2}{*}{$\begin{array}{c}\text { Q2 } \\
\text { (kkal) }\end{array}$} & \multirow[b]{2}{*}{$\begin{array}{c}\text { Q3 } \\
\text { (kkal) }\end{array}$} \\
\hline & $\begin{array}{c}\text { Arang } \\
\text { Tinja }\end{array}$ & $\begin{array}{l}\text { Tetes } \\
\text { Tebu }\end{array}$ & $\begin{array}{l}\text { Lumpur } \\
\text { Lapindo }\end{array}$ & & & \\
\hline 1 & $30 \%$ & $10 \%$ & $20 \%$ & 965,00 & 968,00 & 963,00 \\
\hline 2 & $30 \%$ & $20 \%$ & $30 \%$ & 1016,74 & 1019,74 & 1014,74 \\
\hline 3 & $30 \%$ & $30 \%$ & $40 \%$ & 1261,55 & 1264,55 & 1259,55 \\
\hline 4 & $40 \%$ & $10 \%$ & $30 \%$ & 1290,86 & 1293,86 & 1288,86 \\
\hline 5 & $40 \%$ & $20 \%$ & $40 \%$ & 1545,44 & 1548,44 & 1543,44 \\
\hline 6 & $40 \%$ & $30 \%$ & $20 \%$ & 1651,90 & 1654,90 & 1649,90 \\
\hline 7 & $50 \%$ & $10 \%$ & $40 \%$ & 1674,70 & 1677,70 & 1672,70 \\
\hline 8 & $50 \%$ & $20 \%$ & $20 \%$ & 1762,10 & 1765,10 & 1760,10 \\
\hline 9 & $50 \%$ & $30 \%$ & $30 \%$ & 1742,20 & 1745,20 & 1740,20 \\
\hline
\end{tabular}


Febi Rahmadianto, Analisis Campuran Lumpur dan Tetes Tebu pada ...

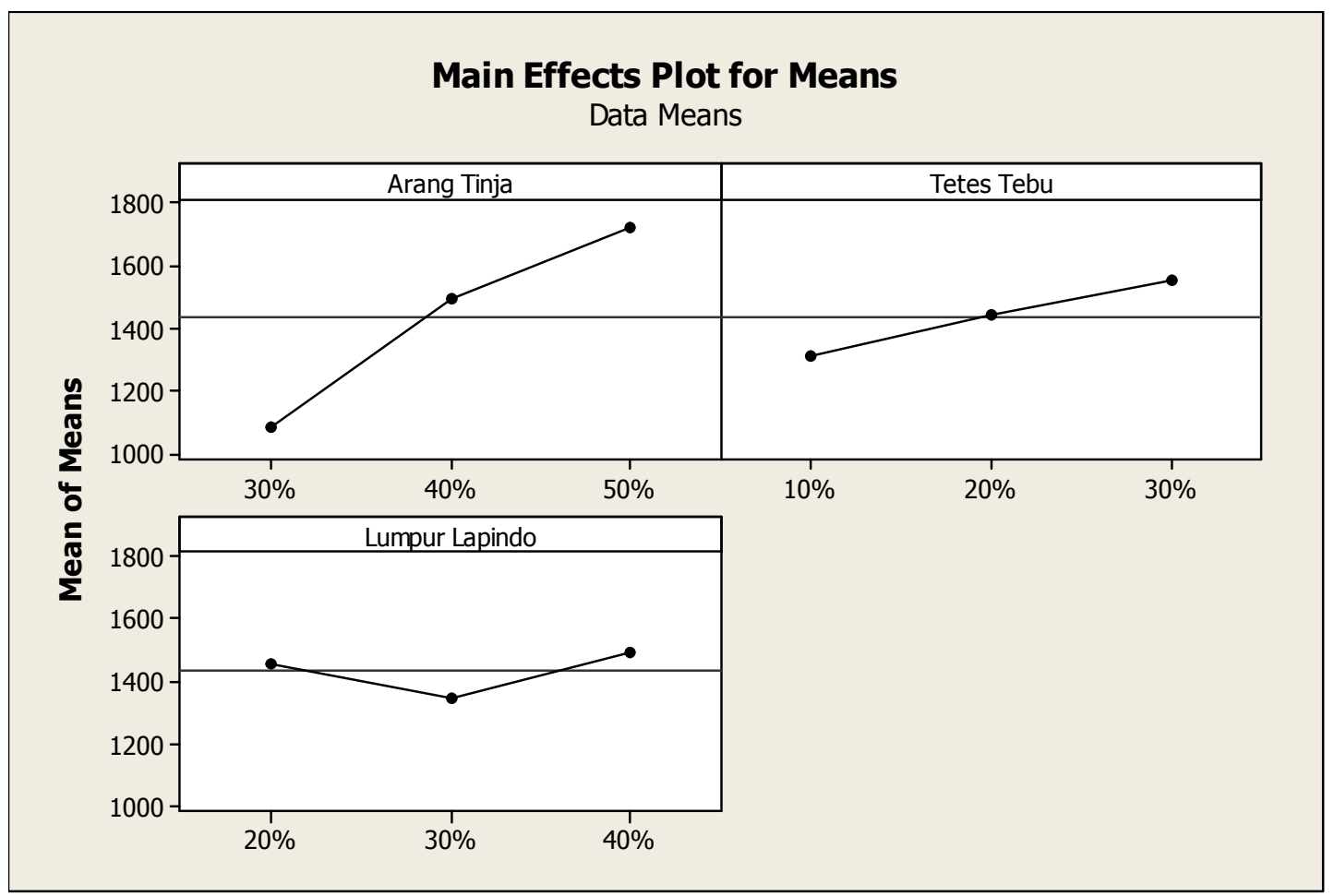

(a)

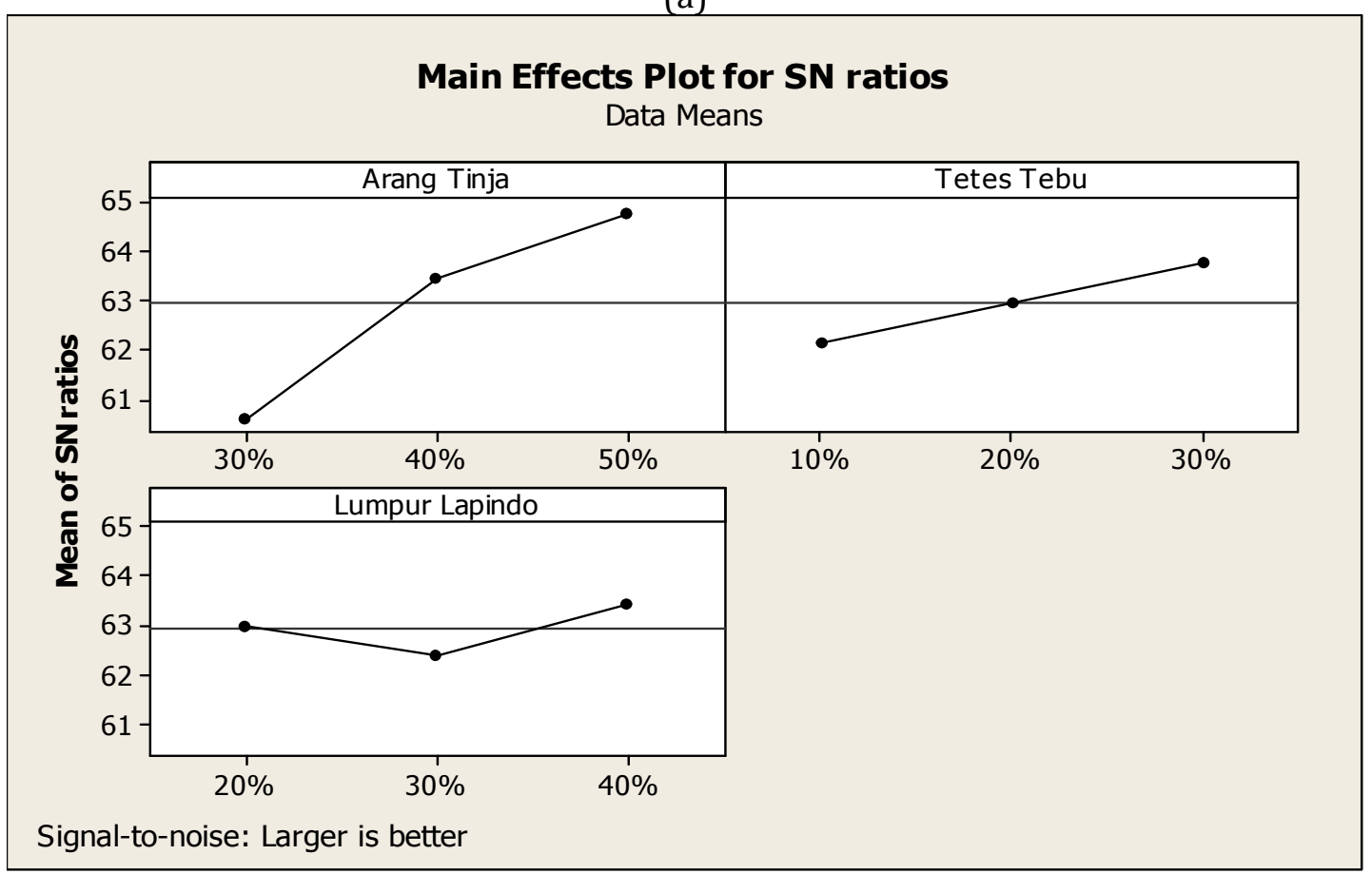

(b)

Gambar 1. Hasil analisis dengan metode Taguchi: (a) Main Effects Plot for Means dan (b) Main Effects Plot for SN ratios

\section{KESIMPULAN}

Setelah menganalisa data yang diperoleh dari penelitian dan membahasnya, dapat disimpulkan sebagai berikut: rasio campuran arang tinja ayam dengan tetes tebu, lumpur 
lapindo dan, tetes tebu + lumpur lapindo dalam briket memberi pengaruh terhadap nilai kalor pembakaran briket. Semakin bertambah rasio campuran maka meningkatkan nilai kalor yang dihasilkan dari pembakaran briket. Sehingga, pada campuran arang tinja ayam 50\% dengan tetes tebu 30\% + lumpur lapindo 40\% menghasilkan nilai kalor tertinggi sebesar 1762.433 kkal. Lebih lanjut, kenaikkan nilai kalor, laju pembakaran, dan laju massa disebabkan bertambahnya rasio campuran yang banyak mengandung kadar $\mathrm{C}$ (carbon) sehingga mempercepat pembakaran dalam briket, apabila sebaliknya jika bertambahnya rasio yang mengandung air maka akan menurun karna unsur hydrogen yang terkandung dalam air susah atau sulit terbakar.

\section{REFERENSI}

[1] S. Kang, R. Miao, J. Guo, and J. Fu, "Sustainable Production of Fuels and Chemicals from Biomass over Niobium Based Catalysts: A Review," Catal. Today, no. October, 2020.

[2] T. Kan, V. Strezov, T. Evans, J. He, R. Kumar, and Q. Lu, "Catalytic pyrolysis of lignocellulosic biomass : A review of variations in process factors and system structure," Renew. Sustain. Energy Rev., vol. 134, no. September, p. 110305, 2020.

[3] M. Syamsiro and H. Saptoadi, "Pembakaran Briket Biomassa Cangkang Kakao: Pengaruh Temperatur Udara Preheat," Semin. Nas. Teknol., vol. 2007, no. November, pp. 1-10, 2007.

[4] P. Suwandono and A. Hardianto, "Pengaruh Temperatur Pirolisis terhadap Kinetik Rate dan Volume Tar pada Limbah Serbuk Kayu Mahoni," R.E.M (Rekayasa Energi Manufaktur) J., vol. 4, no. 1, pp. 9-17, 2019.

[5] H. Nurdin, H. Hasanuddin, and D. Darmawi, "Karakteristik Nilai Kalor Briket Tebu Tibarau Sebagai Bahan Bakar Alternatif," INVOTEK J. Inov. Vokasional dan Teknol., vol. 18, no. 1, pp. 19-24, 2018.

[6] M. I. Hutasuhut, "Analisis Perpindahan Kalor Kondensor Pada Proses Distilasi Bioetanol Sebagai Biofuel Dari Campuran Limbah Buah Salak Dengan Limbah Air Kelapa," J. Mech. Eng. Manuf. Mater. Energy, vol. 2, no. 2, p. 43, 2018.

[7] A. J. Zulfikar, "The Flexural Strength of Artificial Laminate Composite Boards made from Banana Stems," Budapest Int. Res. Exact Sci. J., vol. 2, no. 3, pp. 334-340, 2020.

[8] A. J. Zulfikar, "Numerical Simulation on The Onion Dryer Frame Capacity of 5 kg/hour," JMEMME, vol. 2, no. 02, pp. 86-92, 2018.

[9] J. Ren and Y. Liu, "Journal of Hazardous Materials Letters Progress and prospects of produced gas utilization from biomass tar reforming," J. Hazard. Mater. Lett., vol. 1, no. December, pp. 1-6, 2020.

[10] Syahrul, Y. A. Padang, and N. Sakban, "Pengaruh Kombinasi Limbah Kotoran Ternak Ayam Dengan," Din. Tek. Mesin, vol. 5, no. 2, pp. 122-130, 2015.

[11] S. Syahrul and Nurcahyati, "Pengaruh Variasi Temperatur Pirolisis Terhadap Kadar Hasil Dan Nilai Kalor Briket Campuran Sekam Padi-Kotoran Ayam,” Din. Tek. Mesin, vol. 5, no. 1, pp. 16-24, 2015.

[12] M. Y. Yuhazri, A. J. Zulfikar, and A. Ginting, "Fiber Reinforced Polymer Composite as a Strengthening of Concrete Structures: A Review Fiber Reinforced Polymer Composite as a Strengthening of Concrete Structures : A Review," in Materials Science and Engineering, 2020, p. 13.

[13] B. Das, V. Mukherjee, and D. Das, "Optimum placement of biomass DG considering hourly load demand," Energy Clim. Chang., vol. 1, no. July, pp. 1-6, 2020.

[14] E. Kethobile, C. Ketlogetswe, and J. Gandure, "Heliyon Torrefaction of non - oil Jatropha curcas L . ( Jatropha ) biomass for solid fuel," Heliyon, vol. 6, no. September, pp. 1-10, 2020.

[15] A. Rahmansyah, A. J. Zulfikar, and B. Umroh, "Manufacture of Water Pipe From Clampshell Powder Materials," J. Mech. Eng. Manuf. Mater. ENERGY, vol. 2, no. 2, pp. 73-77, 2018.

[16] W. Liu, C. Liu, P. Gogoi, and Y. Deng, "Overview of Biomass Conversion to Electricity and Hydrogen and Recent Developments in Low-Temperature Electrochemical Approaches," Engineering, vol. 6, no. 12, pp. 1351-1363, 2020. 